\title{
Role of inflammation in oral carcinogenesis (Part I): Histological grading of malignancy using a binary system
}

\author{
MARTA RABELLO PIVA ${ }^{1}$, LÉLIA BATISTA DE SOUZA ${ }^{3}$, PAULO RICARDO SAQUETE MARTINS-FILHO ${ }^{1}$, \\ ROSILENE CALAZANS SOARES ${ }^{2}$, THIAGO DE SANTANA SANTOS ${ }^{4}$ and EMANUEL SÁVIO DE SOUZA ANDRADE ${ }^{5}$
}

\author{
Departments of ${ }^{1}$ Oral Pathology and ${ }^{2}$ Morphology, Federal University of Sergipe, Bairro Sanatório, CEP 49060-100, \\ Aracaju, Sergipe; ${ }^{3}$ Department of Oral Pathology, Federal University of Rio Grande do Norte, Campus Universitário \\ Lagoa Nova, CEP 59072-970, Natal, Rio Grande do Norte; Departments of ${ }^{4}$ Oral and Maxillofacial Surgery \\ and ${ }^{5}$ Oral Pathology, Pernambuco University, CEP 54753-220, Camaragibe, Pernambuco, Brazil
}

Received February 2, 2011; Accepted July 1, 2011

DOI: $10.3892 / \mathrm{ol} .2011 .382$

\begin{abstract}
The aim of the present study was to assess the suppressant role of the inflammatory infiltrate in oral carcinogenesis through the immunohistochemical expression of CD8 and FOXP3 and to discuss how representative this expression proved, as well as other parameters considered to be of prognostic value. A total of 20 cases of oral epithelial dysplasia and 40 cases of oral squamous cell carcinoma were selected. The criteria suggested by the World Health Organization were used for the histological grading of dysplasia. For carcinoma, a binary method was developed for the present study using parameters such as type of invasion, maturity, presence of epithelial masses and dysmorphism of the masses. Immunohistochemical analysis was performed for assessment of the expression of anti-CD8 and anti-FOXP3 in cases of dysplasia and carcinoma. Although the inflammatory infiltrate was more intense in the majority of carcinomas, it exercised a protective role in the dysplasia cases, as CD8 expression was significantly greater. Although a correlation was found between CD8 and the intensity of the inflammatory infiltrate in the carcinoma cases, CD8 demonstrated $>5 \%$ expression in only $32.5 \%$ of the cases, compared to $80 \%$ of the dysplasia cases. Thus, we suggest that the inflammatory infiltrate should not be used as a parameter in routine examinations, as it plays different roles in the various stages of carcinogenesis. The histological grading system for malignancy employed in the present study is indicated for the assessment of oral squamous cell carcinoma.
\end{abstract}

\section{Introduction}

Broders was a pioneer in the classification of oral squamous cell carcinoma. The considerable variation in the histological

Correspondence to: Professor Marta Rabello Piva, Rua Cláudio Batista s/n, Bairro Sanatório, CEP 49060-100, Aracaju, SE, Brazil E-mail: pmartins-filho@hotmail.com

Key words: carcinoma, cytokines, immunohistochemistry, inflammation aspect of this condition led to the development of a number of systems for the histological grading of malignancy. These systems were designed to allow for an interpretation of the aggressiveness of the tumor (1). In 1920, Broders (2) used cell pleomorphism and keratin production as parameters for the assessment of cell differentiation and the number of mitoses for the assessment of tumor growth. In 1941, these parameters were correlated to tumor prognosis (3). Following this period, other systems were used in the histological grading of malignant tumors (Table I) (4-7). In 1998, Bryne et al (8) suggested that only the front of the tumor invasion should be assessed using the degree of keratinization, nuclear pleomorphism, invasion pattern and inflammatory infiltrate as parameters. Based on this system, it has been suggested that cells at the front of the tumor invasion exhibit different molecular characteristics to those at the surface areas of the tumor, and that interactions between the tumor and host in this region are 'crucial to the dissemination of the neoplasm', making this an essential region for the determination of prognosis.

Kurokawa et al (1) studied the relationship between the scores obtained using Bryne's method and the prognosis of patients with squamous cell carcinoma of the tongue. Results showed that patients with a score below 8 had a more positive prognosis, whereas those with a score of 11 or higher had a poorer prognosis. According to Costa et al (9), the histological grading of the deepest sections of the tumor directly affect patient survival due to the fact that tumor cells in these sites are undifferentiated. The authors found a predominantly discrete inflammatory infiltrate in cases of aggressive squamous cell carcinoma when correlated with the development of metastasis in cervical lymph nodes (TNM II/IV). Da Silveira et al (10) found that positive CD8 and CD25 inflammatory cells had a greater involvement in tumors of the lower lip and found that the anti- $\zeta$ transmembrane molecule, which is responsible for translating the bonding of the antigen to the extracellular receptor in activating signals to the interior of the cell, was more pronounced in cases without metastasis, regardless of the anatomic site. The author states that the inflammatory infiltrate exerted a certain impact on the aggressiveness of squamous cell carcinoma of the tongue and lower lip when assessed using Bryne's method. To a certain 
Table I. Parameters used in the various systems for the histological grading of malignancy.

\begin{tabular}{|c|c|c|c|}
\hline Authors & Year & Parameters & Refs. \\
\hline Wahi & 1971 & $\begin{array}{l}\text { Keratinization of individual cells, formation of horn pearls, presence of } \\
\text { intercellular bridges, number and aspect of mitosis figures, degree of cell } \\
\text { and nuclear pleomorphism and presence of multi-nucleated giant cells. }\end{array}$ & (4) \\
\hline Jakobsson et al & 1973 & $\begin{array}{l}\text { Neoplastic structure, keratinization, nuclear pleomorphism, number of mitoses, } \\
\text { mode and stage of invasion, vascular invasion and lymphoplasmocyte } \\
\text { inflammatory infiltrate. }\end{array}$ & $(5)$ \\
\hline $\begin{array}{l}\text { Crissman, Gluckman, } \\
\text { Cummings }\end{array}$ & 1984 & $\begin{array}{l}\text { Degree of keratinization, nuclear pleomorphism, number of mitoses, } \\
\text { invasion pattern, inflammatory infiltrate and vascular invasion. }\end{array}$ & (6) \\
\hline $\begin{array}{l}\text { Anneroth, Batsakis, } \\
\text { Luna }\end{array}$ & 1987 & $\begin{array}{l}\text { Degree of keratinization, cell pleomorphism, number of mitoses, } \\
\text { invasion pattern, stage of invasion and lymphoplasmocyte inflammatory } \\
\text { infiltrate. }\end{array}$ & (7) \\
\hline
\end{tabular}

extent, this effect may be a contributing factor to the controversy regarding the use of this parameter as a morphological indicator of aggressiveness, as the vast majority $(80 \%)$ of the samples exhibited an inflammatory infiltrate ranging from moderate to intense.

Human tumors activate CD4 or CD8 lymphocytes, depending on the processing pathway to trigger the immune response. Moreover, control of the tumor depends on the magnitude of the initial immune response and the capacity to sustain this response for a prolonged period of time (11). The main anti-tumor defense mechanism is the death of tumor cells by CD8 T lymphocytes, also known as cytotoxic T lymphocytes, which are capable of identifying and killing potentially malignant cells that express peptides derived from mutant cell proteins or oncogenic viral proteins associated with $\mathrm{MHC}$ class I. The involvement of CD4 T lymphocytes appears to be related to the production of TNF by macrophages and INF $\gamma$ by the Th1 population. Moreover, these lymphocytes may be responsible for the increase in the expression of MHC-I by tumor cells, resulting in the sensitization of CD8 T lymphocytes and consequent lysis of the tumor cells by the perforin/ granzyme system or through the bonding of Fas in the tumor cells with Fas-L (CD95) from the lymphocytes. Therefore, the suppression of CD4 Th1 lymphocytes has been shown to result in tumor progression (12). However, the immunosuppressive property of CD4 T cells was associated with a low survival rate among patients with ovarian cancer (13). On the other hand, certain authors do not support the hypothesis that the infiltration of CD4 T cells alone is responsible for this lower survival rate, but that the effect of the modulation of CD4 over the benefits of CD8 depends on the number of regulating $\mathrm{T}$ cells in the CD4 population (14).

Active suppression by regulating cells is one of the various mechanisms used to keep the immune response under control, in particular $\mathrm{CD} 4{ }^{+} \mathrm{CD} 25^{+} \mathrm{T}$ cells $\left(\mathrm{T}_{\mathrm{reg}}\right)$, which constitutively express CTLA-4, GITR and Forkhead Box P3 (FOXP3) molecules (15). Attention has been given to the study of FOXP3, which establishes and maintains the genetic program of $\mathrm{T}_{\text {reg }}$ and acts as a negative regulator of the activation of $T$ cells and possibly as a transcriptional effector of anti-inflammatory cytokine programs (16).
Chronic inflammation as a risk factor for cancer was first conceived by Virchow in the early 19th century and reported by Weitzman and Gordon in the association of various chronic inflammatory diseases, including irritable bowel syndrome, atrophic gastritis, chronic colecistitis and reflux esophagitis, with the development of cancer (17). The advent of molecular biology has enabled a number of studies to address the relationship between the tumor and peritumoral stroma, with its evident contribution to tumor growth, invasion and metastasis (18-24). Subsequently, it has become easier to suggest the involvement of cytokines and inflammatory cells in tumor development and progression as compared to an anti-tumor response from the host, as proposed in a number of other studies $(5,7,8)$.

The aim of the present study was to assess the suppressant role of the inflammatory infiltrate in oral carcinogenesis through the immunohistochemical expression of CD8 and FOXP3 and to discuss how representative this expression is, as well as other parameters considered to be of prognostic value.

\section{Materials and methods}

A total of 20 cases of oral epithelial dysplasia and 40 cases of oral squamous cell carcinoma were randomly selected from the archives of the Pathological Anatomy Service of the Federal University of Sergipe and the Pathological Anatomy Laboratory of the Oral Pathology Sector of the Federal University of Rio Grande do Norte, in Brazil. The study received approval from the Research Ethics Committee of the latter institution (process no. 233/2007).

The hematoxylin and eosin-stained slides were viewed under a light microscope and examined in a double-blind manner by two histopathologists. The criteria of the World Health Organization were used for the histological grading of the dysplasia (25). For carcinoma cases, a method was developed for the present study using well-established parameters in the literature, based on Wahi (4). The proposed method considered the following parameters: i) type of invasion, which reveals a greater or lesser speed in the growth and/or invasion, ii) maturity of the epithelial cells, iii) presence of epithelial masses between the lining of the epithelium or ulcerated tissue surface 
Table II. Parameters assessed for the definition of stage of oral squamous cell carcinoma.

\begin{tabular}{|c|c|c|c|c|}
\hline \multirow[b]{2}{*}{ Score } & \multicolumn{2}{|c|}{ Invasive front } & \multicolumn{2}{|c|}{ Epithelial masses } \\
\hline & Type & Maturity & Presence & Dysmorphism \\
\hline 0 & Masses or trabecules & Mature & Absent & Low \\
\hline 1 & Nests or strings & Immature & Present & High \\
\hline
\end{tabular}

Table III. Stages of oral squamous cell carcinoma according to the binary numeral system for each of the parameters.

\begin{tabular}{|c|c|c|c|c|c|}
\hline Situation & Type of invasion & Maturity & Presence of masses & Dysmorphism & Stage \\
\hline 1 & 0 & 0 & 0 & 0 & I \\
\hline 2 & 0 & 0 & 0 & 1 & I \\
\hline 3 & 0 & 0 & 1 & 0 & I \\
\hline 4 & 0 & 0 & 1 & 1 & I \\
\hline 5 & 0 & 1 & 0 & 0 & I \\
\hline 6 & 0 & 1 & 0 & 1 & I \\
\hline 7 & 0 & 1 & 1 & 0 & I \\
\hline 8 & 0 & 1 & 1 & 1 & II \\
\hline 9 & 1 & 0 & 0 & 0 & II \\
\hline 10 & 1 & 0 & 0 & 1 & II \\
\hline 11 & 1 & 0 & 1 & 0 & II \\
\hline 12 & 1 & 0 & 1 & 1 & II \\
\hline 13 & 1 & 1 & 0 & 0 & II \\
\hline 14 & 1 & 1 & 0 & 1 & II \\
\hline 15 & 1 & 1 & 1 & 0 & II \\
\hline 16 & 1 & 1 & 1 & 1 & II \\
\hline
\end{tabular}

and the invasive front, and iv) dysmorphism of the epithelial masses, revealing the incapacity of normal differentiation among these cells. A binary numeral system, using the digits 0 and 1 , was adopted to characterize each of these parameters (Table II). After analysis of all possible combinations, the cases were grouped and classified as stage I (low-grade) or stage II (high-grade) (Table III) to enable the comparative study of these stages with Bryne's grading system (8) and CD8 and FOXP3 expression.

To pair the scores of Bryne's grading system with those obtained in the binary method, the cases with scores of 4-8 and 3-6 were considered as stage I (low-grade), whereas cases with scores of 9-16 and 7-12 were considered as stage II (high-grade) in Bryne's classification. Bryne's grading system for the invasive front was analyzed with and without the inflammatory response parameter. The $\kappa$ test was used to measure the correlation between the method proposed in this study and Bryne's grading system.

Immunohistochemical analysis was performed for assessment of the expression of anti-CD8 and anti-FOXP3 in cases of dysplasia and carcinoma. Paraffin-embedded specimens were cut $(3 \mu \mathrm{m})$ and the slices were mounted on glass slides prepared with an organosilane-based adhesive (3-aminopropyltriethoxysilane, Sigma Chemical Co, St. Louis, MO, USA). Antibodies directed against the proteins studied were then maintained overnight, along with the Dako CD8/144B clone at a dilution of 1:200 for $60 \mathrm{~min}$, and the FOXP3 (H190) clone (Santa Cruz Biotechnology, Santa Cruz, CA, USA) at a dilution of 1:100. Antigen recovery was performed with Tris-EDTA at $\mathrm{pH}$ 9.0, using the SABC and Envision-HRP methods. For the negative controls, the primary antibodies were omitted. For the positive controls, a previously tested periapical granuloma was used. Following the classification of the cases of dysplasia and carcinoma, a semi-quantitative analysis was performed on the CD8 and FOXP3 expression, with reactions of a brown coloration considered positive, regardless of intensity. The percentage of positive cells was calculated for each case, classifying those with $<5 \%$ labeled cells as low expression, those with $5-50 \%$ labeled cells as moderate expression and those with $>50 \%$ labeled cells as high expression, following the criteria proposed by Abbas et al (26).

The statistical analysis was performed using the SPSS 13.0 program for Windows. The $\chi^{2}$ test and Fisher's exact test were employed to determine associations in the distribution of the data between the two stages of the carcinoma obtained by the binary numeral system and the parameters used in this assessment. The non-parametric Mann-Whitney test was used to determine the hypothesis of equality in CD8 and FOXP3 expression with regard to the types of lesion and histological grade of carcinoma. The Friedman ANOVA test was used for comparison between the grades of dysplasia in relation to CD8 and FOXP3 expression. The Spearman's rank 
Table IV. Descriptive analysis of the dysplasia and oral squamous cell carcinoma cases.

\begin{tabular}{|c|c|c|}
\hline Lesions & No. of cases & $\begin{array}{c}\text { Relative } \\
\text { frequency }(\%)\end{array}$ \\
\hline
\end{tabular}

\begin{tabular}{|c|c|c|}
\hline \multicolumn{3}{|l|}{ Dysplasia $(n=20)$} \\
\hline \multicolumn{3}{|l|}{ Grade } \\
\hline Mild & 9 & 45 \\
\hline Moderate & 3 & 15 \\
\hline Severe & 8 & 40 \\
\hline \multicolumn{3}{|l|}{ Inflammatory infiltrate } \\
\hline Mild & 5 & 25 \\
\hline Moderate & 10 & 50 \\
\hline Intense & 5 & 25 \\
\hline \multicolumn{3}{|l|}{ Carcinoma $(n=40)$} \\
\hline \multicolumn{3}{|l|}{ Invasive front } \\
\hline \multicolumn{3}{|l|}{ Type } \\
\hline $\begin{array}{l}\text { Masses or trabecules } \\
\text { (score 0) }\end{array}$ & 24 & 60 \\
\hline $\begin{array}{l}\text { Nests or strings } \\
\text { (score I) }\end{array}$ & 16 & 40 \\
\hline \multicolumn{3}{|l|}{ Maturity } \\
\hline Mature (score 0) & 23 & 57.5 \\
\hline Immature (score I) & 17 & 42.5 \\
\hline \multicolumn{3}{|l|}{ Epithelial masses } \\
\hline \multicolumn{3}{|l|}{ Presence } \\
\hline Absent (score 0 ) & 13 & 32.5 \\
\hline Present (score I) & 27 & 67.5 \\
\hline \multicolumn{3}{|l|}{ Dysmorphism } \\
\hline Low (score 0 ) & 16 & 40 \\
\hline High (score I) & 24 & 60 \\
\hline \multicolumn{3}{|l|}{ Stage } \\
\hline I & 17 & 42.5 \\
\hline II & 23 & 57.5 \\
\hline \multicolumn{3}{|c|}{ Inflammatory infiltrate (stage I) } \\
\hline Mild & 2 & 11.8 \\
\hline Moderate & 4 & 23.5 \\
\hline Intense & 11 & 64.7 \\
\hline \multicolumn{3}{|c|}{ Inflammatory infiltrate (stage II) } \\
\hline Mild & 9 & 39.1 \\
\hline Moderate & 5 & 21.8 \\
\hline Intense & 9 & 39.1 \\
\hline
\end{tabular}

correlation coefficient was used to investigate the correlation between inflammatory infiltrate intensity and positivity for CD8 and FOXP3. P<0.05 was considered to be statistically significant.

\section{Results}

Of the 20 cases of dysplasia, $45 \%$ were classified as mild, $15 \%$ as moderate and $40 \%$ as severe. In most cases, the inflammatory infiltrate was moderate. In relation to oral squamous cell carcinoma, the results demonstrated good replicability of the binary method compared to Bryne's grading system $(\mathrm{k}=0.590$; $\mathrm{p}<0.0001)$, even when the inflammatory response parameter was excluded $(\mathrm{k}=0.688 ; \mathrm{p}<0.0001)$. A total of $42.5 \%$ of the oral squamous cell carcinomas were classified as low-grade (stage I) and $57.5 \%$ as high-grade (stage II), according to the histological grading system developed. A total of $64.7 \%$ of the low-grade cases revealed intense inflammatory infiltrate, in contrast to $34.8 \%$ of the high-grade cases. The descriptive analysis of the dysplasia and oral squamous cell carcinoma is shown in Table IV.

The stages of the oral squamous cell carcinomas were significantly associated with the type of invasive front, cell maturity and the presence of masses between the invasion front and surface of the lesion, as well as the dysmorphism of the cells (Table V). CD8 expression was found to be significantly higher in the dysplasia cases (Fig. 1A). No differences were noted in the CD8 and FOXP3 expression levels between the grades of dysplasia and carcinoma (Figs. 1B and 1C). In the carcinoma cases, inflammatory infiltrate intensity had a direct, significant correlation with CD8 (Table VI).

\section{Discussion}

The considerable variation in the histological aspect of oral epidermoid carcinoma has led, to the development of a number of systems for the histological grading of malignancy designed to allow an interpretation of the aggressiveness of the tumor. However, all of the systems, with the exception of Wahi's classification, considered the inflammatory infiltrate as a parameter of aggressiveness. In the grading system developed for the present study, four established parameters were considered (type of invasion, maturity, presence of epithelial masses and dysmorphism), and the results of this new type of assessment were then compared with Bryne's grading system, obtaining good replicability between the two methods.

In relation to the analysis of the invasive front, it was observed that when the invasion occurred in the form of nests or strings, the tumor had a high degree of aggressiveness, whereas when the invasion occurred in masses or trabecules, the tumor was less aggressive. In the assessment of cell maturity, there was a predominance of mature cells at the invasive front in stage I cases, whereas immature cells predominated in stage II cases. However, immaturity cannot be used for the assessment of cell pleomorphism, as suggested in Bryne's grading system, since it is manifested in the course of the differentiation process. In Bryne's method, this evaluation is incoherent, since it is performed only at the invasive front, where most cells are immature.

While the type of invasion associated with cell maturity in the invasion front demonstrates the speed of tumor growth, the presence of tumor masses between the lining of the epithelium or ulcerated surface and the invasive front denote the existence of a 'time' necessary for these cells to undergo differentiation and demonstrate (through dysmorphism) whether or not this differentiation was successful, relying on its end product, keratin, for this assessment. Therefore, superficial masses may not represent the site in which the main reactions led by inflammatory cytokines occur, but the site where the result of these masses is observed. 
Table V. Classification of oral squamous cell carcinoma according to the parameters proposed for this study.

Histological grade of malignancy

Parameters no. $(\%)$

$\begin{array}{lcrl}\text { Invasive front } & & & \\ \text { Type } & 17(100) & 7(30.5) & <0.05^{\mathrm{a}} \\ \text { Masses or trabecules } & 0(0) & 16(69.5) & <0.05^{\mathrm{a}} \\ \quad \text { Nests or strings } & 15(88.2) & 7(30.5) & \\ \text { Maturity } & 2(11.8) & 16(69.5) & <0.05^{\mathrm{a}} \\ \quad \text { Mature } & & & \\ \text { Immature } & & 4(17.4) & <0.05^{\mathrm{a}} \\ \text { Epithelial masses } & 9(53.0) & 19(82.6) & \\ \text { Presence } & 8(47) & 6(25.0) & 18(75.0) \\ \quad \text { Absent } & 10(62.5) & 6(37.5) & \\ \quad \text { Present } & & \\ \text { Dysmorphism } & & \\ \text { Low } & & & \\ \text { High } & \end{array}$

$\chi^{2}$ and Fisher's exact tests. ${ }^{\mathrm{a}} \mathrm{P}<0.05$, statistically significant.

A

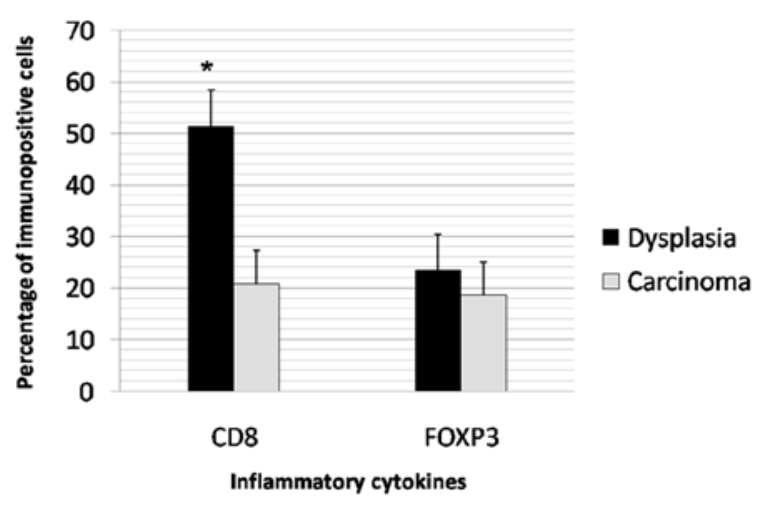

B

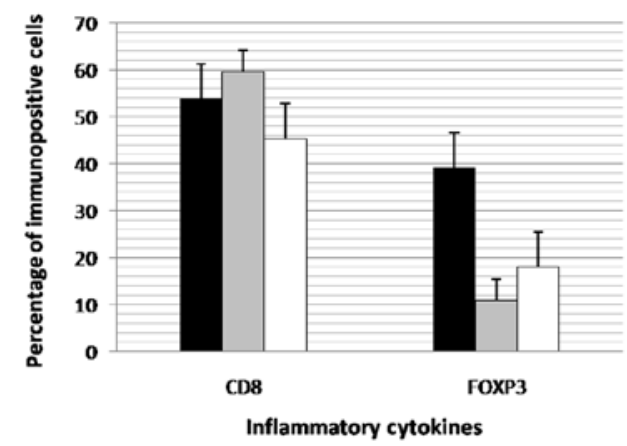

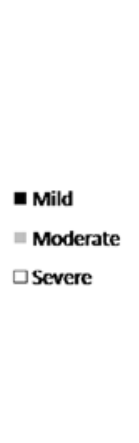
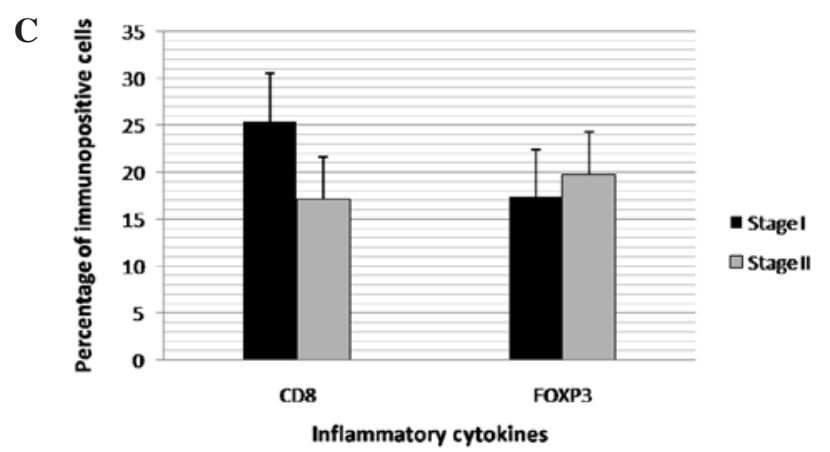

Figure 1. Expression of CD8 and FOXP3 according to (A) the type of lesion, (B) histological grades of dysplasia, and (C) stages of oral squamous cell carcinoma. The percentage of immunopositive cells is shown in the hatched columns. Bars are the mean \pm SD. The expression of CD8 in dysplasia was found to be higher than in carcinoma $\left({ }^{*} \mathrm{p}<0.00001\right)$.

In cases where the tumor is in a phase of proliferation, the majority of cells at the invasive front are immature. This is contrary to the process observed when growth is slow, where keratin production and accumulation occurs, thereby giving volume to surface masses. Thus, the molecular characteristics may differ in areas of proliferation, which would be expected 
Table VI. Correlation between inflammatory infiltrate intensity and positivity for CD8 and FOXP3 expression.

Inflammatory infiltrate intensity

\begin{tabular}{|c|c|c|c|c|c|c|c|c|c|c|c|c|}
\hline \multirow[b]{2}{*}{ Markers } & \multicolumn{6}{|c|}{ Dysplasia $(\mathrm{n}=20)$} & \multicolumn{6}{|c|}{ Carcinoma $(\mathrm{n}=40)$} \\
\hline & Mild & $\begin{array}{l}\text { Mod. } \\
\text { no. }(\%)\end{array}$ & Int. & Total & $\mathrm{r}$ & P-value & Mild & $\begin{array}{l}\text { Mod. } \\
\text { no. }(\%)\end{array}$ & Int. & Total & $\mathrm{r}$ & P-value \\
\hline \multicolumn{13}{|l|}{ CD8 } \\
\hline$<5 \%$ & $2(40)$ & $1(10)$ & $1(20)$ & $4(20)$ & & & $11(100)$ & $6(60)$ & $10(50)$ & $27(67.5)$ & & \\
\hline $5-50 \%$ & $2(40)$ & $2(20)$ & $0(0)$ & $4(20)$ & 0.391 & N.S. & $0(0)$ & $1(10)$ & $2(10)$ & $3(7.5)$ & 0.365 & $<0.05^{\mathrm{a}}$ \\
\hline$>50 \%$ & $1(20)$ & $7(70)$ & $4(80)$ & $12(60)$ & & & $0(0)$ & $2(20)$ & $8(40)$ & $10(25.0)$ & & \\
\hline \multicolumn{13}{|l|}{ FOXP3 } \\
\hline$<5 \%$ & $3(60)$ & $6(60)$ & $2(40)$ & $11(55)$ & & & $7(63.6)$ & $6(60)$ & 11 (57.9) & $24(60.0)$ & & \\
\hline $5-50 \%$ & $1(20)$ & $2(20)$ & $2(40)$ & $5(25)$ & 0.109 & N.S. & $2(18.2)$ & $3(30)$ & $6(31.6)$ & $11(27.5)$ & 0.018 & N.S. \\
\hline$>50 \%$ & $1(20)$ & $2(20)$ & $1(20)$ & $4(20)$ & & & $2(18.2)$ & $1(10)$ & $2(10.5)$ & $5(12.5)$ & & \\
\hline
\end{tabular}

Spearman rank correlation coefficient. ${ }^{a} \mathrm{P}<0.05$, statistically significant. NS, not significant.

even in normal epithelium, with greater intensity at the invasive front of highly proliferative tumors that are made up almost exclusively of immature cells. In tumors with slow growth, either atypical or well-differentiated, it is difficult to determine this difference in the labeling pattern between the masses and the invasive front; the difference is observed between the two types of tumors. Thus, the analysis of the invasive front is as crucial in the assessment of this growth potential as the assessment of the masses in relation to their differentiation capacity, both of which are significant in the assessment of carcinoma behavior.

A number of authors have stated that the presence of inflammatory infiltrate is common in tumors of the oral cavity (27). In the present study, inflammatory infiltrate was present in all cases of dysplasia and carcinoma, but was more intense in the latter. An anti-tumor defense role has been attributed to inflammatory infiltrate by authors from Jakobsson et al (5) to Bryne et al (8). However, recent studies, including that carried out by Da Silveira et al (10), warn of the possibility of this infiltrate exerting another role, or of not even exerting an antitumor defense role at all, termed 'immunological evasion'. It may be suggested that the absence of inflammatory infiltrate in the initial phase of development of oral carcinoma facilitates the action of the aggressor, which may have autonomy for progression, thereby triggering a reaction, albeit small, from the host, which is immediately enlisted by the tumor cells to work in their favor. This is in agreement with the $81.8 \%$ of high-grade carcinomas detected among the 11 cases that exhibited mild inflammatory infiltrate in the present study, and is also in agreement with the findings described by Costa et al (9). It is well known that a lack of response from the host, whether or not it is due to an absence or inadequacy of an inflammatory response, may be related to aggressiveness; however, the opposite is not valid. Therefore, the intensity of pure and simple inflammation cannot be used as a parameter for prognosis, as it may take on different roles in the various stages of carcinogenesis. It is crucial to understand what its presence indicates and the manner in which it acts on tumor transformation, progression and invasion. However, findings by Bryne et al (8) are somewhat valid regarding the significance of the interaction between the inflammatory infiltrate (regardless of its role) and the tumor cells at the invasive front, although the molecular differences in the area of the front of the tumor invasion may depend on the speed of the growth and vice versa.

Comparative studies of dysplasia and carcinoma have demonstrated significant molecular alterations, which do not occur between the histological grades of carcinoma (26). In the present study, a greater expression of CD8 was detected in the cases of dysplasia than in those of carcinoma, suggesting an initially protective function of the inflammatory infiltrate. However, the maintenance of the stimulus and greater or lesser expression of other inflammatory cytokines may favor transformation, followed by invasion. Although the carcinoma cases exhibited a more intense inflammatory reaction and an increase in CD8 expression associated with this intensity, CD8 expression remained far lower than in the cases of dysplasia. Further studies are required to assess the roles of this and other inflammatory cytokines in carcinogenesis and the possibility of using these cytokines in antitumor therapy.

In conclusion, we suggested that intensity of the inflammatory infiltrate should not be used as a parameter in the prognostic assessment of oral squamous cell carcinoma, as it exercises different functions in the various stages of carcinogenesis. The histological grading of malignancy is a reliable prognostic indicator, particularly when linked to immunohistochemical analysis. The proposed histological grading of malignancy has greater prognostic value due to the fact that it does not use the intensity of the inflammatory infiltrate as a parameter, and the binary system reduces subjectivity in the evaluation. The anti-tumor reaction exerted by CD8 T lymphocytes occurs with greater frequency in cases of dysplasia, suggesting that a high concentration of this cell population slows down the transformation and invasion process. Moreover, although the intense inflammatory infiltrate has a positive correlation to CD8, the anti-tumor defense action is minimal, as only $32.5 \%$ 
of oral squamous cell carcinomas exhibited a greater than $5 \%$ labeling.

\section{References}

1. Kurokawa H, Zhang M, Matsumoto S, Yamashita Y et al: The high prognostic value of the histologic grade at the deep invasive front of tongue squamous cell carcinoma. J Oral Pathol Med 34: 329-333, 2005.

2. Broders AC: Squamous-cell epithelioma of the lip: a study of five hundred and thirty-seven cases. J Am Med Assoc 6: 656-664, 1920 .

3. Broders AC: The microscopic grading of cancer. Surg Clin North Am 21: 947-961, 1941

4. Wahi PM: Tipos histológicos de tumores orales y orofaringeos. Ginebra: Organización Mundial de la Salud, 1971.

5. Jakobsson PA, Eneroth GM, Killander D, Moberger G and Artenson B: Histologic classification and grading of malignancy in carcinoma of the larynx (a pilot study). Acta Radiol Ther Phys Biol 12: 1-8, 1973

6. Crissman JD, Liu WY, Gluckman JL and Cummings G: Prognostic value of histopathologic parameters in squamous cell carcinoma of the oropharynx. Cancer 54: 2995-3001, 1984.

7. Anneroth G, Batsakis JG and Luna M: Review of the literature and a recommended system of malignancy grading of squamous cell carcinoma. Scand J Dent Res 95: 222-249, 1987.

8. Bryne M: Is the invasive front of an oral carcinoma the most important area for prognostication? Oral diseases 4: 70-77, 1998

9. Costa Ade L, Araújo Júnior RF and Ramos CC: Correlation between TNM classification and malignancy histological feature of oral squamous cell carcinoma. Braz J Otorhinolaryngol 71: $181-187,2005$

10. Da Silveira EJ, Miguel MC, Lima KC, Freitas Rde A, de Morais Mde L and Queiroz LM: Analysis of local immunity in squamous cell carcinoma of the tongue and lower lip. Exp Mol Pathol 88: 171-175, 2010.

11. Sabel MS, Hess SD, Egilmez NK, Conway TF Jr, Chen FA and Bankert RB: CTLA-4 blockade augments human T lymphocytemediated suppression of lung tumor xenografts in SCID mice. Cancer Immunol Immunother 54: 944-952, 2005.

12. Chang MC, Chiang CP, Lin CL, Lee JJ, Hahn LJ and Jeng JH: Cell-mediated immunity and head and neck cancer: with special emphasis on betel quid chewing habit. Oral Oncol 41: 757-775, 2005.

13. Curiel TJ, Coukos G, Zou L et al: Specific recruitment of regulatory $\mathrm{T}$ cells in ovarian carcinoma fosters immune privilege and predicts survival. Nat Med 10: 942-949, 2004.
14. Sato E, Olson SH, Ahn J et al: Intraepithelial CD8 ${ }^{+}$tumor-infiltrating lymphocytes and a high $\mathrm{CD} 8^{+} /$regulatory $\mathrm{T}$ cell ratio are associated with favorable prognosis in ovarian cancer. Proc Natl Acad Sci USA 102: 18538-18543, 2005.

15. Fontenot JD, Gavin MA and Rudensky AY: FoxP3 programs the development and function of $\mathrm{CD} 4{ }^{+} \mathrm{CD} 25^{+}$regulatory T cells. Nat Immunol 4: 330-336, 2003.

16. Fontenot JD, Rasmussen JP, Williams LM, Dooley JL, Farr AG and Rudensky AY: Regulatory T cell lineage specification by the forkhead transcription factor FoxP3. Immunity 22: 329-341, 2005.

17. Weitzman SA and Gordon LI: Inflammation and cancer: Role of phagocyte-generated oxidants in carcinogenesis. Blood 76: 655-663, 1990.

18. Balkwill F and Mantovani A: Inflammation and cancer: back to Virchow? The Lancet 85: 473-483, 2001.

19. Coussens LM and Werb Z: Inflammatory cells and cancer think different! J Exp Med 193: 23-26, 2001.

20. O'Byrne KJ and Dalgleish AG: Chronic immune activation and inflammation as the cause of malignancy. Br J Cancer 85: 473-483, 2001

21. Yan L, Zucker S and Toole BP: Roles of the multifunctional glycoprotein, emmprin (basigin; CD 147), in tumour progression. Thromb Haemost 93: 199-204, 2005.

22. Mignona MD, Fedele S, Lo Russo L, Lo Muzio L and Bucci E: Immune activation and chronic inflammation as the cause of malignancy in oral lichen planus: is there any evidence? Oral Oncol 40: 120-130, 2004.

23. Aggarwal BB, Shishodia S, Sandur SK, Pandey MK and Sethi G: Inflammation and cancer: How hot is the link? Biochem Pharmacol 72: 1605-1621, 2006.

24. Vigneswaran N, Beckers S and Waigel S: Increased EMMPRIN (CD 147) expression during oral carcinogenesis. Exp Mol Pathol 80: $147-159,2006$

25. Warnakulasuriya S, Reibel J, Bouquot J and Dabelsteen E: Oral epithelial dysplasia classification systems: predictive value, utility, weaknesses and scope for improvement. J Oral Pathol Med 37: 127-133, 2008.

26. Abbas NF, Labib El-Sharkawy S, Abbas EA and Abdel Monem El-Shaer M: Immunohistochemical study of p 53 and angiogenesis in benign and preneoplastic oral lesions and oral squamous cell carcinoma. Oral Surg Oral Med Oral Pathol Oral Radio Oral Endod 103: 385-390, 2007.

27. Hoffmann TK, Bier H and Whiteside TL: Targeting the immune system: novel therapeutic approaches in squamous cell carcinoma of the head and neck. Cancer Immunol Immunother 53: 1055-1067, 2004. 